\title{
Study of the Effect of CR on the Performance and Emissions of Diesel Engine Using Butanol-diesel Blends
}

\author{
Vaibhav R. Wakode* and A. B. Kanase-Patil \\ Automotive Engineering, Mechanical Engineering Department, Savitribai Phule Pune University, Pune, Maharashtra, India
}

Accepted 15 June 2016, Available online 20 June 2016, Special Issue-5 (June 2016)

\begin{abstract}
Diesel engines are widely used in transportation and power generation sectors in the world. The harmful exhaust emissions from these engines are responsible for degradation of environmental quality. The fuel economy of these engines is also an important factor, as petroleum diesel is on the verge of depletion. There is need to substitute diesel fuel with alternative fuel which will improve the engine performance and emissions. Among the various alternatives to diesel, alcohols are promising fuels. Out of alcohols, only lower alcohols like ethanol have been studied for testing engine performance. This paper investigates the significance of butanol as an alternative to diesel. Various butanoldiesel blends were prepared and tested for physical properties. The engine output characteristics are tested with diesel for various compression ratios. The results of engine performance and emissions for diesel are presented.
\end{abstract}

Keywords: diesel engines, compression ratio, performance, emissions, butanol.

\section{Introduction}

Nowadays automobile engine manufacturers have to follow the strict emission standards. The engine performance especially fuel economy needs to be improved. To satisfy both these requirements is a huge challenge for engine manufacturers. To develop the engines require extensive knowledge of the parameters and their relationship with the engine output characteristics. Out of these parameters, the parameters which affect the engine combustion are significant in that, improvement in combustion results in the improvement of engine performance and emissions. Another important parameter is Compression Ratio (CR). For diesel engines, thermal efficiency is a function of CR. Thus, improvement in engine performance is expected with increase of CR. The impact of CR on Brake Thermal Efficiency (BTE), Specific Fuel Consumption (SFC) needs to be checked. Also Carbon monoxide (CO), Hydrocarbons (HC), smoke and Nitrogen oxides (NOx) emissions need to be measured. The effect of CR on engine output was studied by researchers for various fuels. The improvement in engine torque and BSFC was observed with increase in compression ratio. The Carbon monoxide (CO) emissions decreased up to $\mathrm{CR} 16$, and increased again up to CR 18. The Nitrogen oxides (NOx) emissions were found to be increased with increase in CR for biodiesel-diesel blends (EL_Kassaby and Nemit_allah, 2013). For Jatropha oil-diesel blends,

*Corresponding author: Vaibhav R. Wakode with increase in CR and loading, the BTE was improved, but the values were lower than diesel. The CO emissions were higher than diesel and NOx emissions were lower with increase in CR for all fuel blends. (De and Panua, 2014). The performance and emission characteristics for increase in CR were tested for ethanol-diesel blends (Gnanamoorthi and Devaradjane, 2014). At CR 19.5, the BTE values for ethanol-diesel blends were higher than diesel, which showed improvement in BTE with CR. On the other side, the $\mathrm{CO}$ and $\mathrm{HC}$ emissions increased with increase in CR and were higher than diesel. The NOx emissions decreased for ethanol-diesel blends due to higher latent heat of vaporization of ethanol. It was found that lower smoke emissions were observed for ethanoldiesel blends at higher CR values.

Like ethanol, butanol is a biomass-based renewable fuel that can be produced by alcoholic fermentation of the biomass feedstocks (Jin, et al, 2011). Butanol has higher carbon content than ethanol and more oxygen compared to biodiesel. The higher latent heat of vaporization of butanol helps to reduce the temperature inside the engine cylinder. Butanol is a very versatile fuel and fuel extender in both gasoline and diesel engines. It has no solubility problems when blended with diesel and there is no separation in the blends and no additive is needed. Also, butanol has more resistance to water absorption than ethanol, thus causes less corrosion problems and it is more suitable for transportation through existing fuel pipelines than ethanol. Hence, butanol seems a good alternative to diesel in the near future. Hence, butanol-diesel blends 
should be tested for engine performance and emissions.

The engine characteristics of butanol/diesel blends in turbocharged diesel engine were studied (Siwale, et al, 2013). The NO and HC emissions for the blends were slightly higher than diesel with increase in load. The CO emissions decreased with increase in load and percentage blending. At all loads, the soot emission were lower than diesel for all blends.

The investigation of the bus engine characteristics operating on butanol/diesel blends was carried out (Rakopoulos, et al, 2010). The BSFC and BTE values for butanol/diesel blends were comparable with that of diesel values with almost negligible variation. The CO values for blends were equal or less than that of diesel at all loads. The HC emissions for the blends were always higher than that of diesel for all the loads.

The performance of three-cylinder diesel engine was tested with butanol/diesel blends for different speeds and loads (Fernandez, et al, 2012). The lower butanol blends showed lower BSFC with increase in load. For all speeds, the BTE for the blends was higher than that of diesel at full load condition. Thus, improvement in performance was observed with butanol/diesel blends.

\section{Experimental Set up}

The experimental set up consists of single cylinder, four stroke, Variable Compression Ratio (VCR), diesel engine connected to eddy current dynamometer. The CR was varied by tilting cylinder block arrangement. The performance measurement was done by the online performance evaluation software ICEnginesoft, version 9.0. The software generated various combustion and performance related data during engine testing. The five gas exhaust gas analyzer provided by AVL was used for emissions measurement. Also, AVL 437 smoke meter was used for engine-out smoke emissions measurement. Fig. 1 shows the schematic diagram experimental set up.

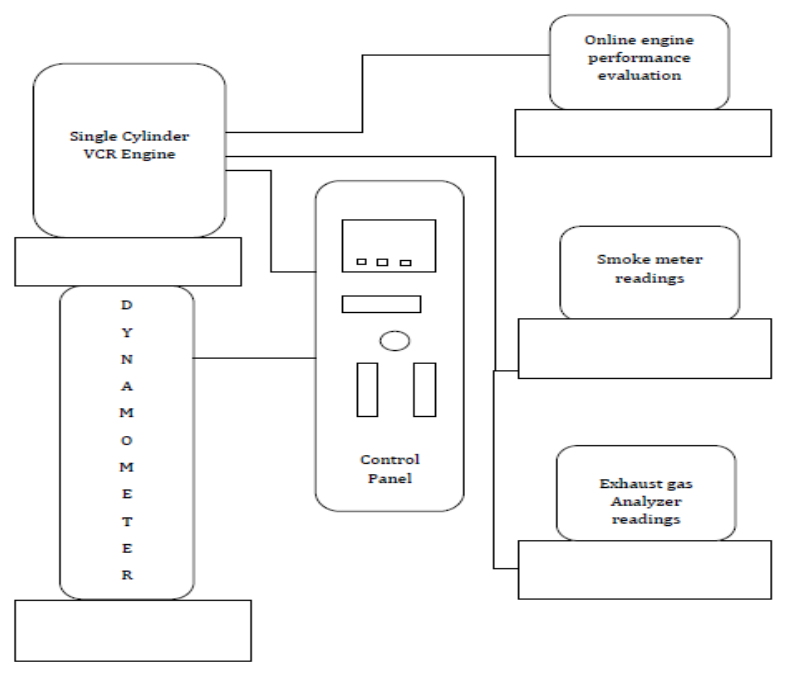

Fig.1 Experimental set up
The engine specifications are mentioned in Table 1.

Table 1 Engine Specifications

\begin{tabular}{|c|c|}
\hline Engine & $\begin{array}{c}\text { Single cylinder, four stroke, VCR } \\
\text { engine, water cooled }\end{array}$ \\
\hline Type & Kirloskar TV1 \\
\hline Power & $3.5 \mathrm{~kW} @ 1500 \mathrm{rpm}$ \\
\hline Bore (mm) & 87.5 \\
\hline Stroke (mm) & 110 \\
\hline Cubic capacity (cc) & 661 \\
\hline CR range & 12 to 18 \\
\hline Injection timing & $23^{\circ} \mathrm{bTDC}$ \\
\hline
\end{tabular}

\section{Preparation of butanol-diesel blends}

As butanol does not have stability problem when mixed with diesel, the blends were prepared by direct mixing. The blends were prepared on the percentage by volume basis. Different blends prepared were B10, $\mathrm{B} 20, \mathrm{~B} 30, \mathrm{~B} 40$ and B50 (B10 shows the blend of 10\% butanol and $90 \%$ diesel likewise for other blends). Blending was done to minimize the gap between properties of diesel and butanol. Viscosity and density are important properties which affect air-fuel mixture preparation and distribution inside the combustion chamber. The viscosity of the blends was measured using Oswald's viscometer and density was measured using $25 \mathrm{ml}$ density bottle. These density and viscosity values were compared with the values from others research work. Fig. 2 to Fig. 5 showed the viscosity and density variation of the blends with the percentage of blending.

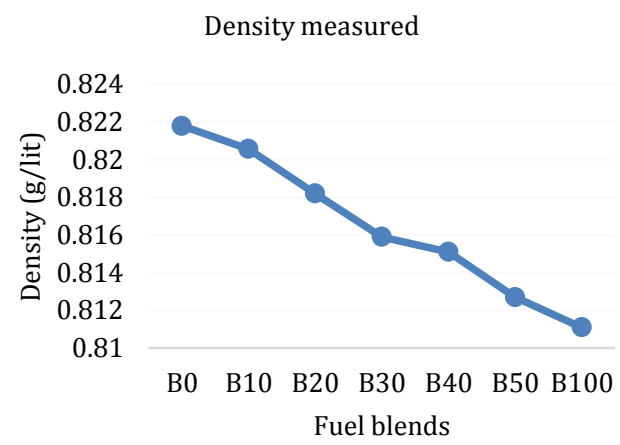

Fig. 2 Measured density variation with percentage blending Density referred

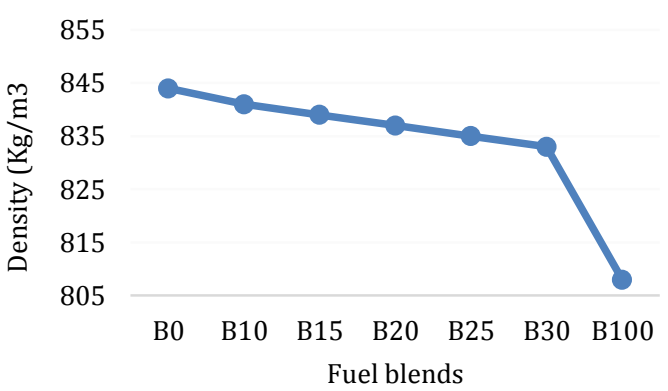

Fig. 3 Referred density variation with percentage blending 


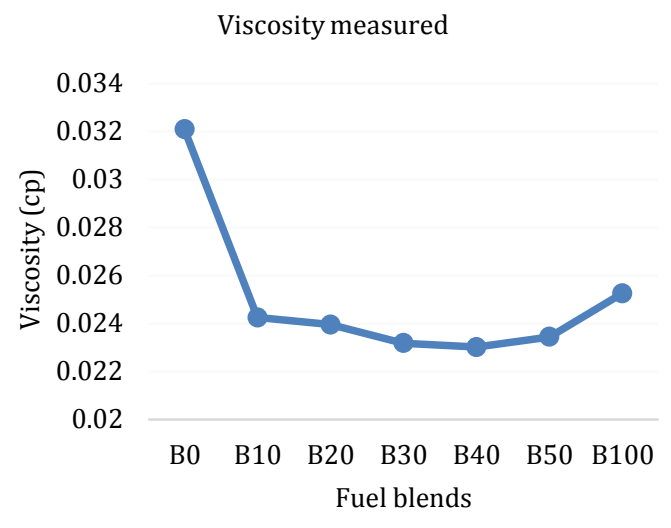

Fig. 4 Referred viscosity variation with percentage blending

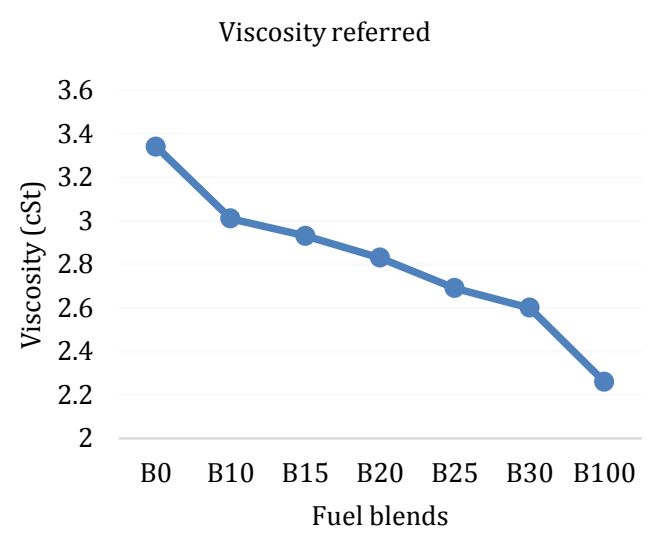

Fig. 5 Referred viscosity variation with percentage blending

\section{Results and discussions}

\subsection{Test results for diesel}

The engine was tested for CR values of 15, 16, 17 and 18 for diesel fuel. The CR was varied by rotating the adjuser provided for tilting the cylinder block by referring to the CR indicator. Fig. 6 and Fig. 7 shows the SFC and BTE variation for different CR values at rated engine load for diesel. It is observed that the engine performance improves with increase in CR. The highest BTE (29.32\%) is observed at CR 17 for rated load for diesel.

The variation of exhaust emissions from the engine for stated range of CR are shown in Fig. 8 to Fig. 13. With increase in $\mathrm{CR}, \mathrm{HC}$ and $\mathrm{CO}$ emissions decrease significantly as can be seen from Fig. 8 and Fig. 10. At lower $\mathrm{CR}$, the temperature inside the engine cylinder is not sufficient to burn the fuel completely, thus $\mathrm{CO}$ emissions increased. The mixture inside the diesel engine cylinder is heterogeneous. So these locally rich or lean air-fuel mixtures do not get sufficient oxygen and/or temperature necessary for the combustion.
Thus HC emissions also increased. From Fig. 9, it is seen that, the $\mathrm{CO}_{2}$ emissions increase gradually with increase in CR. This indicates the occurance of complete combustion with increased CR. Fig. 11 shows that higher the CR values, higher are the NO emissions. This is because, with increase in CR, the pressure and temperature inside the cylinder also increases and at higher temperature, the tendancy of NO formation is higher. Fig. 12 and Fig. 13 shows the variation of smoke absorption coefficient and opacity with CR at rated engine load, respectively. The opacity is the extinction of light between light source and receiver. The absorption coefficient values were lower for CR 15, 16 and 17 and were highest for CR 18.

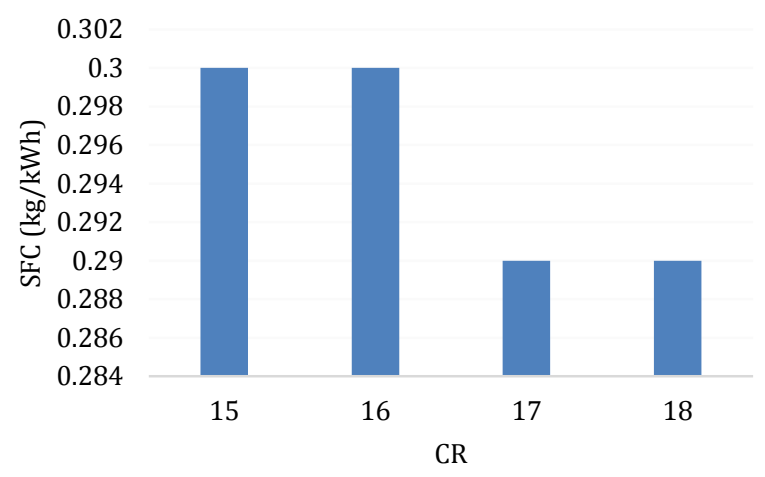

Fig. 6 Variation of SFC with CR at rated engine load

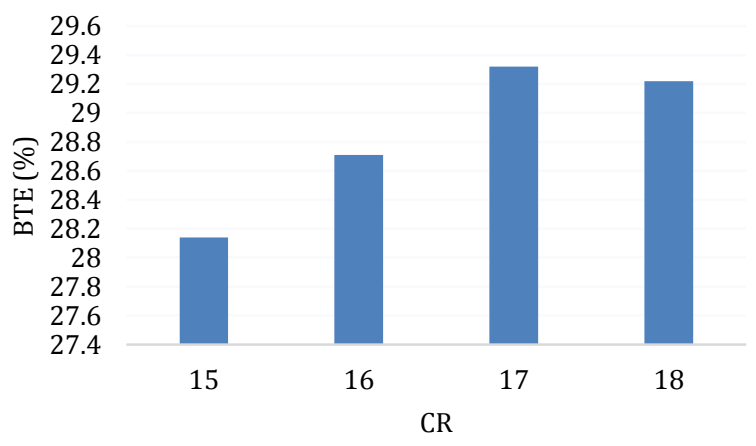

Fig. 7 Variation of BTE with CR at rated engine load

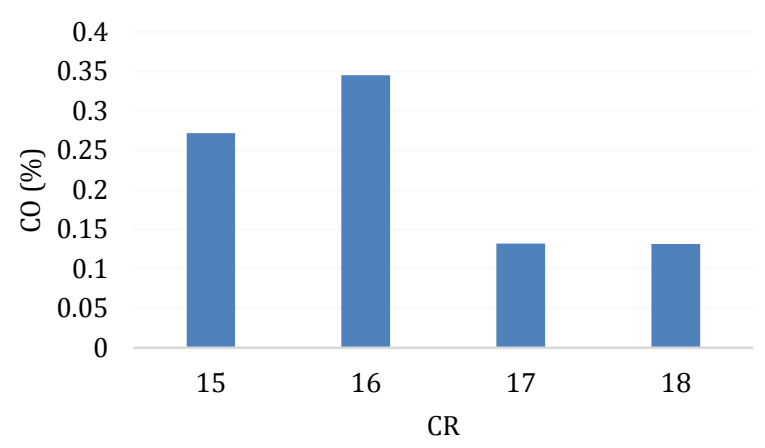

Fig. 8 Variation of CO emissions for different CR values at rated engine load 


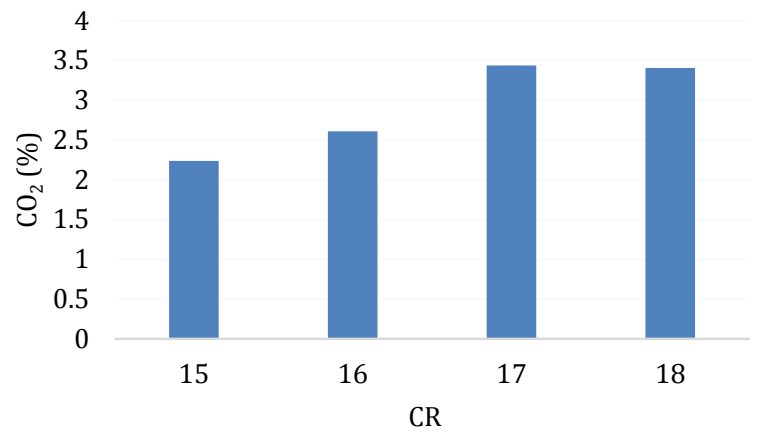

Fig. 9 Variation of $\mathrm{CO}_{2}$ emissions for different $\mathrm{CR}$ values at rated engine load

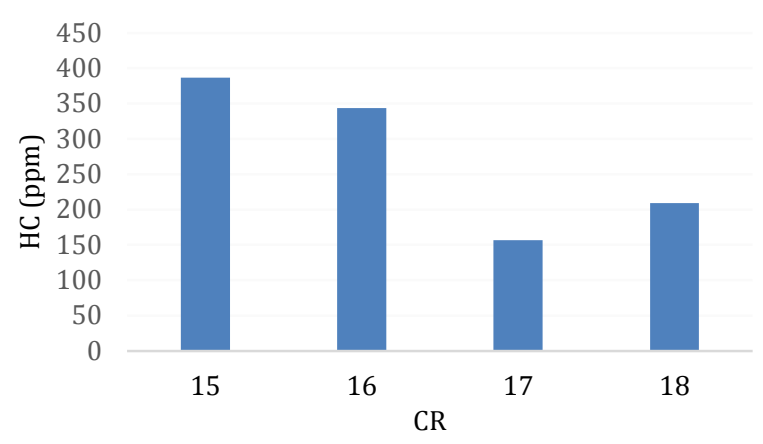

Fig. 10 Variation of HC emissions for different CR values at rated engine load

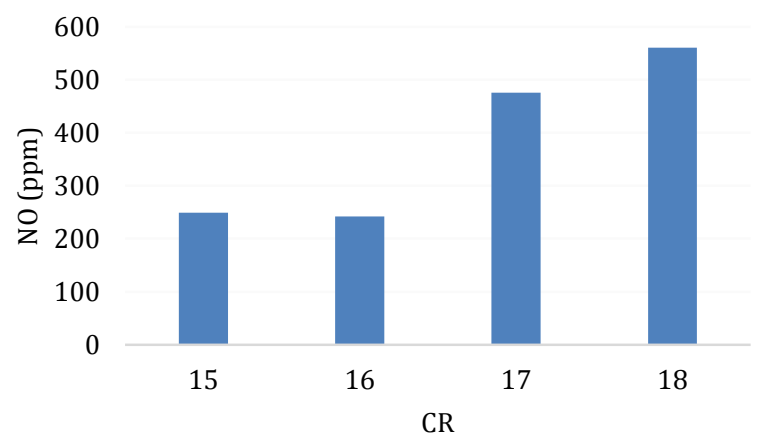

Fig. 11 Variation of NO emissions for different CR values at rated engine load

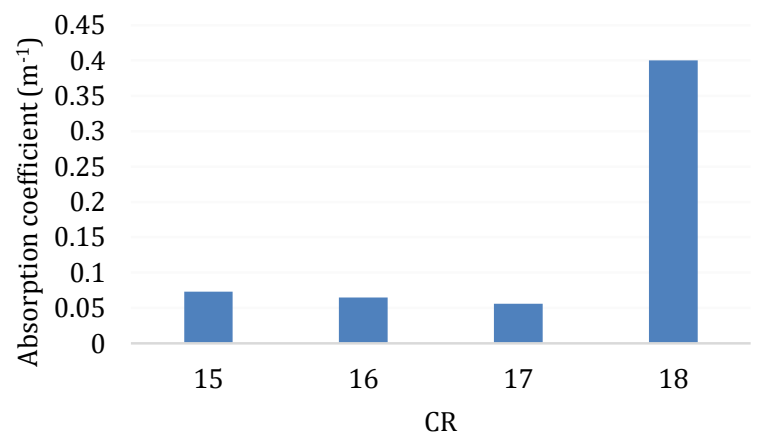

Fig. 12 Variation of absorption coefficient with CR at rated engine load

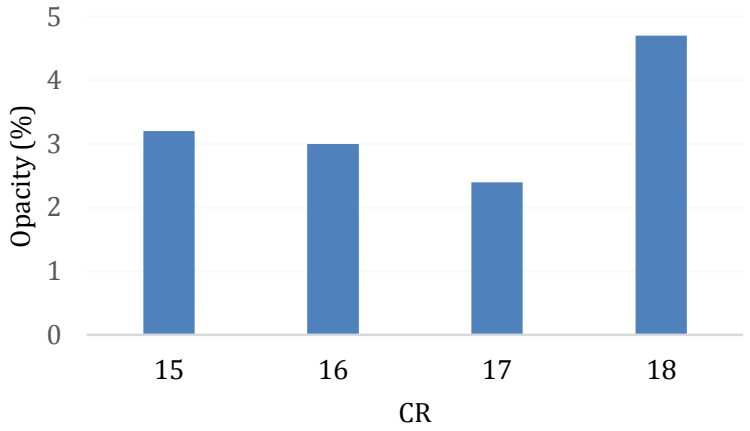

Fig. 13 Variation of opacity with CR at rated engine load

\subsection{Test results for butanol/diesel blends}

The performance and emission characteristics for butanol/diesel blends is predicted from the literature. The lower calorific value of butanol compared to diesel can be compensated by the presence of its oxygen content. With increased CR, the higher temperature and pressure inside the engine cylinder may contribute to the formation of NOx inside the engine if there is sufficient time for nitrogen oxidation. But butanol has higher latent heat of vaporization value than diesel which may contribute to lowering of temperature inside the cylinder and thus NOx. The butanol has higher oxygen content even compared to biodiesel and thus it may lead to complete combustion and formation of $\mathrm{CO}_{2}$. The complete combustion indicates the decrease in $\mathrm{CO}$ formation. The oxygen content in the blend can be helpful for the oxidation of soot generated during the combustion and thus, reduction in smoke emissions is expected.

Also, from the literature, the $\mathrm{HC}$ emissions with butanol/diesel blends were found to be increased with increase in blending and load. The increase in HC emissions may be eliminated by improved combustion at higher CR. Also with increase in load, the BTE and BSFC values were improved for butanol/diesel blends. The higher CR values may further improve the performance.

\section{Conclusions}

From the study, following conclusions are drawn:

1) The comparison between measured and referred viscosity and density values showed quite good agreement for butanol/diesel blends.

2) Increase in $\mathrm{CR}$ resulted in improvement in engine performance in terms of SFC and BTE for diesel.

3) The engine-out $\mathrm{HC}$ and $\mathrm{CO}$ emissions were improved with increase in $\mathrm{CR}$ but with the penalty in $\mathrm{CO}_{2}$ and $\mathrm{NO}$ emissions for diesel fuel.

4) For diesel, the highest smoke emissions were found at CR 18 . 


\section{References}

M. EL_Kassaby, M. A. Nemit_allah, (2013), studying the effect of compression ratio on an engine fueled with waste oil produced biodiesel/diesel fuel, Alexandria Engineering Journal, 52, 1 - 11

B. De, R. S. Panua, (2014), An experimental study on performance and emission characteristics of vegetable oil blends with diesel in a direct injection variable compression ignition engine, Procedia Engineering, 90, 431 $-438$.

V. Gnanamoorthi, G. Devardjane, (2014), Effect of compression ratio on the performance, combustion and emission of DI diesel engine fueled with ethanol - diesel blend, Journal of the Energy Institute, 1 - 8.
C. Jin, M. Yao, H. Liu, C. Lee, J. Ji, (2011), Progress in the production and application of n-butanol as a biofuel, Renewable and Sustainable Energy Reviews, 15, 4080 4106.

L. Siwale, L. Kristof, T. Adam, A. Baraczky, M. Mbarawa, A. Peninger, A. Kolesnikov, (2013), Combustion and emission characteristics of n-butanol/diesel fuel blend in a turbocharged compression ignition engine, Fuel, 107, 409 - 418.

D. C. Rakopoulos, C. D. Rakopoulos, D. T. Hountalas, E. C. Kakaras, E. G. Giakoumis, R. G. Papagiannakis, (2010), Investigation of the performance and emission of bus engine operating on butanol/diesel blends, Fuel, 89, 2781 2790.

J. Campos-Fernandez, J. A. Arnal, J. Gomez, M. P. Dorado, (2012), A comparison of performance of higher alcohol/diesel fuel blends in a diesel engine, Applied energy, 95, $267-275$. 